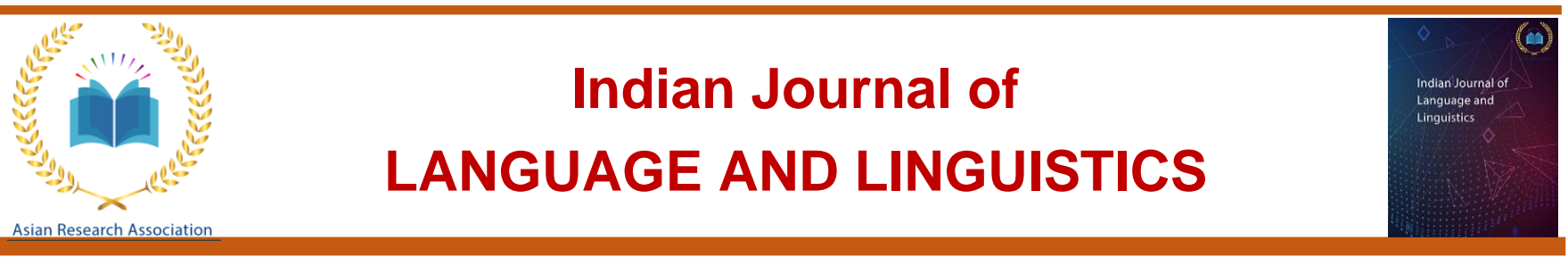

\title{
Derivational Morphology of Assamese Lexical Word Categories
}

\author{
Palash Das a (1D, Madhumita Barbora ${ }^{\mathrm{a},{ }^{*}}$ \\ a Department of English, Tezpur University, Assam-784028, India \\ *Corresponding author Email: barboram@gmail.com \\ DOI: https://doi.org/10.34256/ijll2021
}

Received: 30-09-2020, Revised: 10-10-2020; Accepted: 11-10-2020; Published: 11-10-2020

\begin{abstract}
Word formation by derivation is very productive in Assamese. A significant amount of words in Assamese owe their origin to derivation. The analysis in this paper takes into account the derivational processes related with lexical word categories, and, numerous bound morphemes that are used in the derivational process in the language. This analysis helps us to understand some of the important aspects of Assamese morphology. These aspects are - role of class maintaining and class changing morphemes, derivation of word from synonyms, productivity of derivational morphemes, morphophonemic changes in root as a result of affixation of derivational morphemes, presence of allomorphs of various bound morphemes, ability of a morpheme to derive words from different word categories. The significance of this paper lies in the fact that these word formation processes could help develop morphological rules that can be used for developing computational morphological tools like- stemmer, spell checker, tagger etc.
\end{abstract}

Keywords: Assamese, Lexical words, Derivation morphology, Class maintaining, Class changing.



Mr. Palash Das is currently pursuing his Ph.D. at the Department of English, Tezpur University, Assam. His areas of specialization are morphology and language technology.

\section{Introduction}

It is assumed that the origin of the Assamese language is from the Magadhan group of the Indo-Aryan language family. G. C. Goswami (1982) states: "It is supposed that like other Aryan languages, Assamese was also born from Apabhramsa dialect developed from Magadhi Prakrit of the eastern group of Sanskrit language".

North East India is the home of five language families: Indo-Aryan, Austro-Asiatic, Tibeto-Burman, Tai Kadai and Dravidian. Speakers of these languages have been maintaining a close socio-political-economic relationship from a very long time. Kakati (1941:57- 89) discusses at length about the non-Aryan neighbouring languages impacting on Assamese. Close contact between these language families, especially between the IndoAryan and Tibeto-Burman language families have led to convergence. Before the reorganization of North East India into seven states the entire North East India was known as Assam. Assamese was the official language and Assamese was used as the lingua franca by speakers of different language groups. Due to years of contact and eventual convergence Assamese language has acquired some distinct properties which make it distinct from other Indo-Aryan languages. 


\subsection{Scope of the analysis}

Assamese, with about 15 million $^{1}$ native speakers, is the Eastern-most language of the Indo-Aryan language family. Typologically speaking the morphology of Assamese exhibit both agglutinating and inflectional features. The analysis in this paper takes into account the derivational processes related with lexical word categories in Assamese. This helps us to find out different bound morphemes that are used in the derivational process. An important insight into a major word formation process is provided by the analysis. The analysis will also be helpful for developing morphological rules for Assamese. Morphological rules can be used for developing computational morphological tools like- stemmer, spell checker, tagger etc. for Assamese. In this age of information technology languages need to keep pace with the digital world. Assamese does not have a very strong digital presence. Hence the present analysis will help to bridge the gap to some extent by facilitating morphological rule development which is very crucial for a language like Assamese that lack digital resources.

\section{Derivation}

Trask (1999: 47) defines derivation as a way of constructing new words by adding affixes to existing words. Derivation is one of the basic ways of obtaining new words in most languages. According to Booij (2012:51) derivational process enables the users of a language to create new lexemes. Payne (2006:38) explains derivation in its difference from inflection which is another major word formation process. Derivation is best explained in its difference form inflection which is another major branch of morphology. Inflection is a word formation process that helps us to get grammatically distinct form of the same word. On the other hand derivation helps us to get new words. For example the inflected forms of the word write- writes, writing, written are only grammatically distinct form of the same word. On the other hand writer is a new word obtained with derivation from the word write. Inflectional affixes add grammatical information to the root, but derivational affixes contribute meaning to the root. Haspelmath and Sims (2010:86-89) listed common derivational meanings of word categories using terms like deverbal noun, deadjectival noun, denominal verb, deverbal adjective etc.

Derivation is closely linked with the notion of lexicon in Anderson (1995: 180-184). Lexicon here is not analogous to a dictionary or a kind of list or database. It is the knowledge a speaker has of how words can interpret positions in a syntactic structure. As part of the lexicon this knowledge forms derivational rules. The function of these rules is to establish relation among stems to create new lexical stems on the basis of the existing one when required. Anderson further defines derivation as a class of word formation rules within the lexicon. These rules contain information about the lexical category, syntactic sub-categorization, semantics and argument structure, etc. of the stems to which they apply. Thus, there is not much difference between inflectional and derivational word formation rules. But there is a core difference between both of them. Inflection brings structural changes affecting the phonological form of the word. On the other hand derivation results in the semantic as well as syntactic modification of a word. Derivational pattern in languages can be broadly understood from the schema in Fig. 1.

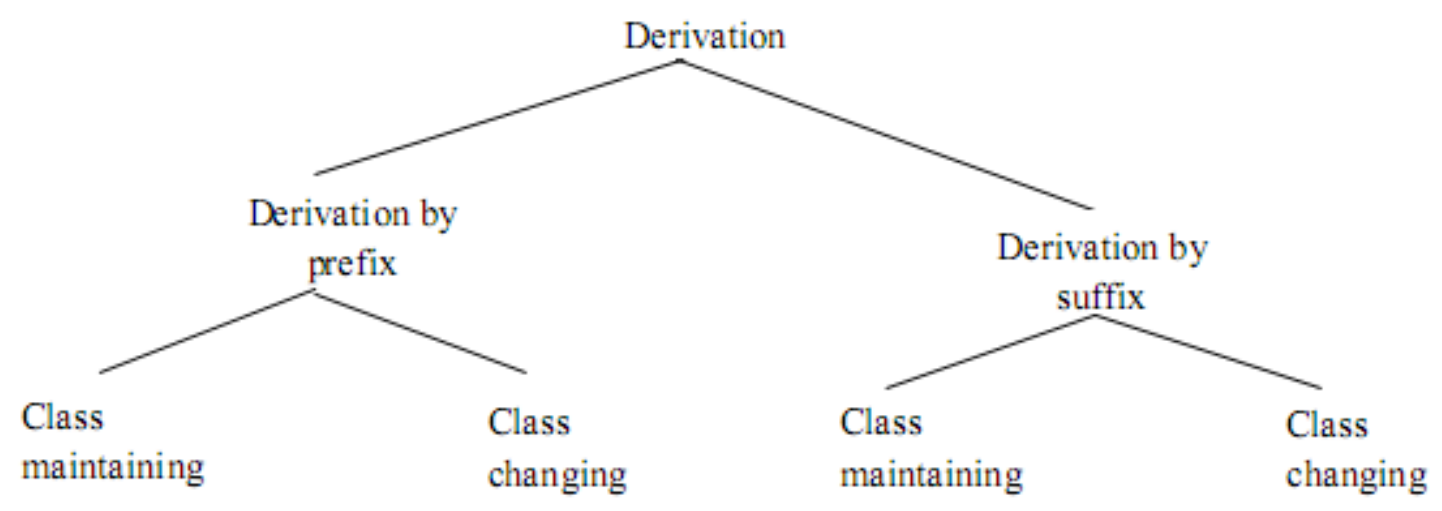

Fig 1 Derivation pattern in Assamese

1 According to 2011 population census 


\subsection{Derivation in Assamese}

A significant amount of words in Assamese owe their origin to derivation. Knowledge about the morpheme structure of Assamese words is very important to understand the derivational word formation process in Assamese. Categories like nouns, adjectives, verbs and adverbs are open class words. These words take derivational suffixes to form new words which may belong to the same category or may form a new category. These derived words can take inflections to indicate its status as a noun, verb, adjective or adverb. In the lines of Hasplemath and Sims (2010: 87) we are going to look into the deverbal noun, deadjectival noun, denominal verb, deverbal adjective etc. These derivational patterns in case of Assamese are discussed below.

\subsection{Derivation of Assamese Nouns}

Creating new words for new concepts is one of the chief functions of derivational morphology. We also have a greater need for naming diverse nominal concepts; this explains why languages generally have more means for deriving nouns than for deriving verbs and adjectives (Haspelmath and Sims 2010: 87). In Assamese, both prefixes and suffixes are used to derive nouns. Use of prefix to derive nouns in Assamese is shown in Table 1.

Table 1 Derivation in Assamese

\begin{tabular}{|c|c|c|c|c|}
\hline Prefix & Root & Gloss & Prefix+root & Gloss \\
\hline כ- & xכmכi & time & כxכmวi & wrong time \\
\hline a- & $\mathrm{kal}_{\mathrm{N}}$ & time & akal $_{N}$ & famine \\
\hline av- & $\mathrm{bat}_{\mathrm{N}}$ & path & arbat $_{N}$ & wrong path \\
\hline эро- & $Z \mathrm{ZXX}_{\mathrm{N}}$ & pride & כрכzכ $X_{N}$ & malign \\
\hline onu- & $\mathrm{pD}_{\mathrm{N}}$ & time & כnupכ $\left.\right|_{N}$ & fraction of time \\
\hline onu- & $\lambda \approx \mathrm{d}^{h_{N}}$ & obstacle & วnuגəd ${ }^{h}{ }_{N}$ & request \\
\hline
\end{tabular}

From Table 1 it can be seen that the prefixes in the table have both negative as well as positive connotation. $\mathbf{x} \mathbf{\jmath m \boldsymbol { i }}$, $\mathbf{p} \mathbf{0 l}$ and $\mathbf{k a l}$ are synonyms i.e. different words with same meaning. However, the difference in their usage is shown in (1).

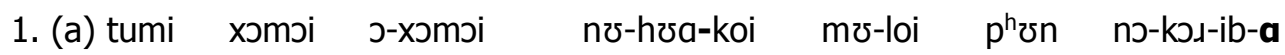

you time wrong time NEG-be-ADVS me-DAT phone NEG-do-FUT-2

Lit. 'You don't call me without considering appropriateness of time.'

'You don't call me at wrong time.'

(b) tumi o-xomวi-t ta-loi na-za-b-a

you DNOM-time-LOC there-DAT NEG-go-FUT-2

Lit: 'You do not go there at wrong time.'

'Don't come at an inconvenient tíme'.

(c) khวan-ग babe a-kal hoi

draught-GEN for DNOM-time be

'Famine is caused by draught.'

(d) pol onu-pol ho-i xəmoi pas hoi

time fraction of time be-NF time pass be

'Time passes in fraction.'

From (1a-d) it can be seen that although the meaning of both xomoi, kal and pol are same the derived

nouns כxכmכi, akal and onupol have different connotation. כxכmכi means 'wrong time' akal means 'famine' and onupol means 'fraction of time'. (1.a) shows that oxכmoi is not followed by any other bound morpheme. But in (1.b) oxכmכi is followed by the locative case marker -t. 


\subsubsection{De-verbal noun $(\mathrm{V} \rightarrow \mathrm{N})$}

Crystal (2008:141) defines de-verbal noun as noun that originates as a verb but used as noun in sentence structure. Deverbal noun in Assamese is shown in Table 2.

Table 2 Deverbal nouns in Assamese

\begin{tabular}{|c|c|c|c|c|}
\hline Root & Gloss & Suffix & Root+ Suffix & Gloss \\
\hline nasv & dance & -כoni & nasoni & dancer \\
\hline $\mathrm{k}^{\mathrm{h}} \varepsilon \mathrm{ll}_{\mathrm{v}}$ & play & -uoi & $\mathrm{k}^{\mathrm{h}}$ cluoin & player \\
\hline $\mathrm{k}^{\mathrm{h}} \mathrm{a} v$ & eat & - כıía & $k^{\text {hasıia }}$ & eater \\
\hline kJdv & do & - б̃ta & kJגช̃ta N & doer \\
\hline $\mathrm{gav}_{\mathrm{v}}$ & sing & -jJk & gajJk $_{N}$ & singer \\
\hline
\end{tabular}

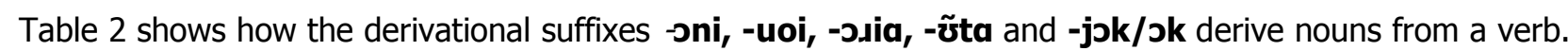
For example, suffixation of -oni to the verb nas 'dance' derives the noun nasoni 'dancer'. Suffixation of -uoi to

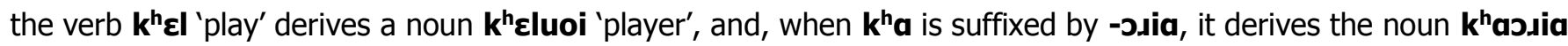

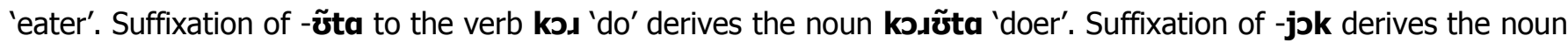
gajjk 'singer' from the verb ga 'singer'. Deverbal nouns in Assamese are shown in (2a-b).
2. (a) nas-Jni- $\varepsilon$
bihu nas-is- $\varepsilon$ dance-NMZ-ERG $b$
ihu dance-PRG-3
(b)
$k^{\text {h }} \varepsilon$ l-uoi-xokol ah-il play-NMZ-COL come-PST
'The dancer is dancing Bihu dance.'
'The players came.'

In (2a) and (2b) the verbs nas 'dance' and $\mathbf{k}^{\mathrm{h}} \boldsymbol{\varepsilon l}$ 'play' are nominalised by the suffixes -oni and -uoi and the derived nominals can function like pure nouns. The derived nominals which occur in the subject position in (2a-

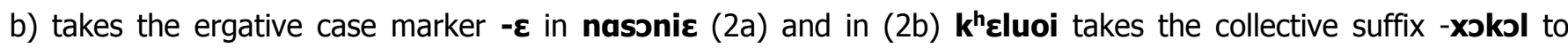
indicate that it patterns like regular nouns. In (2a) the subject is an 'agent' i.e. doer of an action and in (2b) the subject is a 'theme' to which the reference is made.

\subsubsection{Deadjectival noun $(A \rightarrow N)$}

De-adjectival noun involves derivation of a noun from an adjective and Crystal (2008:130) defines it as noun that originates as an adjective but used as noun in sentence structure. Table 3 shows deadjectival nouns in Assamese.

Table 3 Deadjectival nouns in Assamese

\begin{tabular}{|c|c|c|c|c|}
\hline Root & Gloss & Suffix & Root+suffix & Gloss \\
\hline ni.رob & silent & - ota & 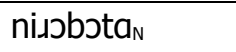 & silence \\
\hline bixEX $_{A D J}$ & special & -otwo & bixexJtw & specialty \\
\hline sh.est ${ }^{\mathrm{h}} \mathrm{J}_{\mathrm{AD}}$ & superior & -two & 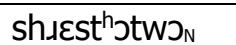 & superiority \\
\hline
\end{tabular}

As evident from Table 3 the derivational suffixes are attached directly to the adjectives in order to derive nouns. These suffixes are further elaborated in (3).

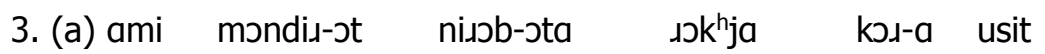 we temple-LOC silent-DNOM maintain do-NF should 'We should maintain silence in temple.' 


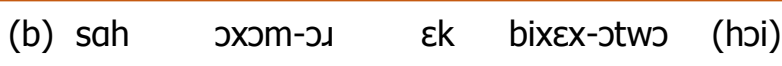
tea assam-GEN one special-DNOM be
'Tea is a specialty of Assam.'

The derived deadjectival noun takes plural marker and classifier as shown in (4a-b).

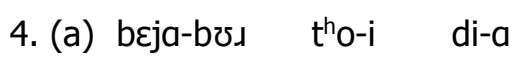
bad-PL keep-CP give-2

'Keep the bad ones.'

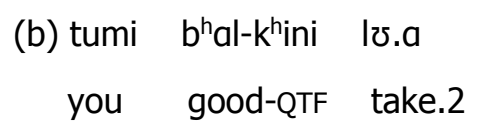

'You take the good ones.'

(4a-b) shows derivation of nouns from adjectives in Assamese. In (4a) the plural marker -bəð is suffixed to the adjective brja 'bad' to derive noun. In (4b) the quantifier - $\mathbf{k}^{\mathbf{h}} \mathbf{i n i}$ is suffixed to the adjective to derive the object noun $\mathbf{b}^{\mathbf{h}} \mathbf{a l k} \mathbf{k}^{\mathbf{h}} \mathbf{i n i}$. The derived nouns $\mathbf{b} \boldsymbol{\varepsilon} \mathbf{j} \mathbf{a b} \boldsymbol{s} \mathbf{s}$ and $\mathbf{b}^{\mathbf{h}} \mathbf{a l} \mathbf{k}^{\mathbf{h}} \mathbf{i n i}$ function as direct object of verb in the sentence structure.

From (3) and (4) we find two types of deadjectival nouns: those in Table 3 which take suffixes like -ota, two etc. and those which do not take a derivational suffix as in (4a-b). But in both (3) and (4) the derived nouns function as nouns. ni.sobota and bixexotwo in (3a-b) are nouns derived from adjectives and function as nouns in

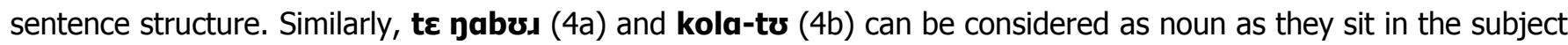
and object position in the sentences without taking a derivational suffix.

\subsubsection{De-nominal nouns $(\mathrm{N} \rightarrow \mathrm{N})$}

De-nominal nouns are nouns derived from another noun. Derivation of denominal nouns in Assamese is shown in Table 4.

Table 4 Derivation of denominal nouns in Assamese

\begin{tabular}{|c|c|c|c|c|}
\hline Root & Gloss & Suffix & Root+Suffix & Gloss \\
\hline golp & story & -kaı & golpokad N & story writer \\
\hline gひlЈkN & globe & 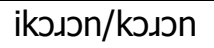 & gסlכkikנכנח & globalization \\
\hline baspJn & steam & -bhวwวn & baspib $^{\text {h}}{ }^{2}{ } n_{N}$ & $\begin{array}{c}\text { act of converting } \\
\text { liquid to steam }\end{array}$ \\
\hline $\operatorname{na} \tilde{\mho}_{N}$ & boat & - & nawدian & boatman \\
\hline bjoktin $_{N}$ & person & -two & bjoktitwวN & personality \\
\hline nagدik $_{N}$ & citizen & -otwว & nagدjikJtwวN & citizenship \\
\hline
\end{tabular}

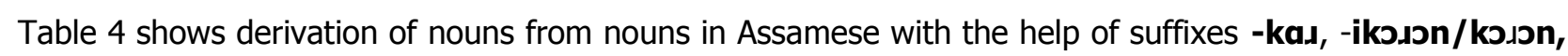

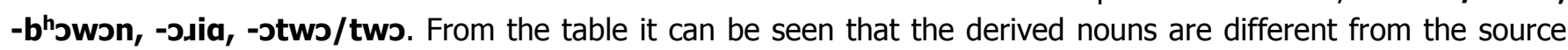
noun in meaning. For example, suffixation of -kas to the noun golpo 'story' derives the noun golpskas 'story

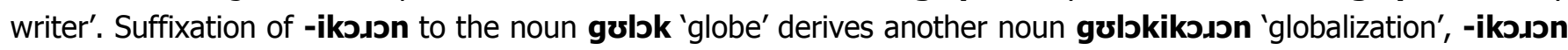

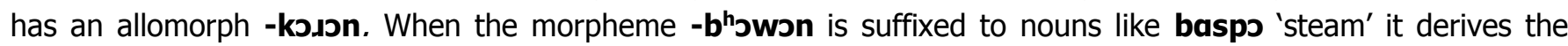

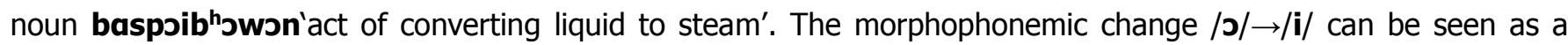

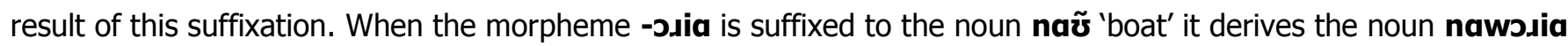

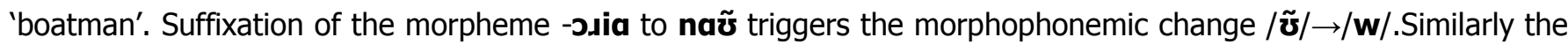
suffix -two derives the noun bjoktitwo 'personality' from the noun bjokti 'person'. -two is one of such suffixes 
which can be used to derive words from more than one word categories. -two has an allomorph -otwo which derives nagosikotwo from nagد.jik. -two can derive noun from adjective (Table 3) and noun form noun (Table 4). The examples in (5a-b) show some denominal nouns in the subject position of the declarative clauses.

5. (a) giti-kaı-zon mə^ $b^{\text {hal }}$ bondh $u$ (hoi)

lyric-DNOM-CLF my good friend be

'The lyricist is my good friend.'



warrior-COL-ERG war start do-FUT-3

'The warriors started the war.'

\subsubsection{De-nominal nouns with negative connotation}

Bound morphemes 0-, dus- and du- derive nouns which have negative connotation as shown in Table5, 6 and 7. These bound morphemes are prefixes and they are class maintaining prefixes. Table 5 shows derivation of denominal nouns with the help of the prefix 0-, followed by Tables 6 and 7 with the dus- and du- prefixes respectively.

Table 5 Derivation by ว- morpheme

\begin{tabular}{|c|l|l|l|l|}
\hline Prefix & Root & Gloss & Prefix+root & Gloss \\
\hline J- & biswax $_{\mathrm{N}}$ & trust & Jbiswax $_{\mathrm{N}}$ & Distrust \\
\hline J- & ${\text { nid }\lrcorner a_{N}}$ & sleep & ${\text { Jnid }\lrcorner a_{N}}_{N}$ & Sleeplessness \\
\hline
\end{tabular}

Table 6 Derivation by dus- morpheme

\begin{tabular}{|c|c|c|c|c|}
\hline Prefix & Root & Gloss & Prefix+root & Gloss \\
\hline dus- & $\mathrm{b}^{\mathrm{h}}$ agjoj & fate/fortune & duub $^{\text {hagjon }}$ & misfortune \\
\hline dus- & $\operatorname{din}_{N}$ & day & $\operatorname{dusdin}_{N}$ & bad day \\
\hline dud- & $\operatorname{nam}_{N}$ & name & duınam $_{N}$ & bad name \\
\hline
\end{tabular}

Table 7 Derivation by du- morpheme

\begin{tabular}{|c|c|c|c|c|}
\hline Prefix & Root & Gloss & Prefix+root & Gloss \\
\hline du- & sinta $_{N}$ & thought & dusintan $_{N}$ & worry \\
\hline du- & xJpbad $_{N}$ & news & duxobbad $_{N}$ & bad news \\
\hline du- & $\mathrm{xaJx}_{\mathrm{N}}$ & courage & $\operatorname{duxaJx}_{N}$ & audacity \\
\hline duh- & xכmכi & time & duhxכmכiN & bad time \\
\hline
\end{tabular}

\subsection{Derivation of Assamese Verbs}

In Assamese verbs can be derived both by prefixation and suffixation. In the sections to follow we will look into the derivation of verbs in the language.

\subsubsection{De-nominal verb $(N \rightarrow V)$ :}

Crystal (2008: 135) defines de-nominal verb as verb that originates as a noun but used as verb in sentence structures. De-nominal verb formation is not very productive in Assamese. 
Table 8 De-nominal verbs in Assamese

\begin{tabular}{|c|c|c|c|c|}
\hline Root & Gloss & Suffix & Root+Suffix & Gloss \\
\hline $\mathrm{g}^{\mathrm{h}_{\mathrm{JSa}}}$ & fist & $-i j a$ & $\mathrm{~g}^{h_{\text {}}}$ sija v & hit with fist \\
\hline SI N N & slap & $-i j a$ & sJija v & to give a slap \\
\hline $\mathrm{p}^{\mathrm{h}} \mathrm{Jni}_{\mathrm{N}}$ & comb & $-j a$ & $\mathrm{p}^{\mathrm{h}} \mathrm{Jnija} \mathrm{v}$ & to comb hair \\
\hline
\end{tabular}

Table 8 shows derivation of a verb from a noun with the derivational suffix -ija. Suffixation of -ija derives

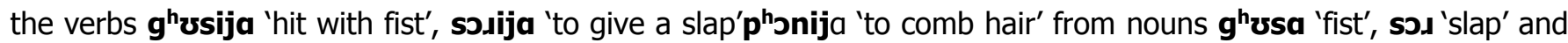
$\mathbf{p}^{\text {honi }}$ 'comb' respectively. Morphophonemic change $/ \mathbf{a} / \rightarrow / \mathbf{i} /$ can be seen as a result of the suffixation of the morpheme -ija with the noun $\mathbf{g}^{\mathrm{h}} \mathbf{z s a}$. There is an instance of vowel assimilation when '-ija' suffixes with $\mathbf{p}^{\text {honi. }} \mathbf{\text { .i } /}$ in -ija gets assimilated with the word final /i/.

In (6) we have instance of de-nominal verbs functioning as a main verb.

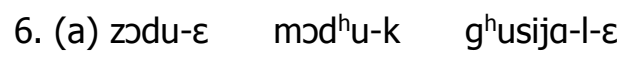

jadu-ERG madhu-ACC fist.DVRB-PST-3

Jadu hit Madhu with fist.'

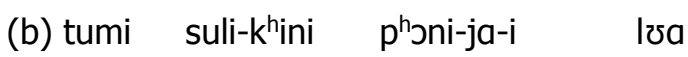

you hair-QTF comb-DVRB-CP take.2

'You comb your hair'

The sentences in (6) show derivation of a verb from a noun with the derivational suffix -- ija /-ja. In (6a) the derivational suffix -ija derives the verb $\mathbf{g}^{\text {h}} \mathbf{u s i j a}$ 'hit with fist' from the noun $\mathbf{g}^{\text {h}} \mathbf{u s a}$ 'fist'. The back open vowel /a/ of the second syllable in $\mathbf{g}^{\text {h }} \mathbf{u s a}$ is dropped and the deverbal morpheme -ija is suffixed to derive the verb $\mathbf{g}^{\text {h}} \mathbf{u s i j a}$. In (6b) the derivational suffix -ja which is an allomorph of -ija, follows the noun $\mathbf{p}^{\text {h }} \mathbf{j n i}$ 'comb' to derive

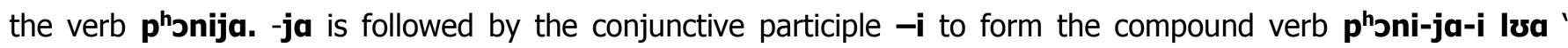
comb' which includes the tense and agreement features

\subsubsection{Deverbal verbs (Negative verbs)}

Barbora (2001:101) states that negatives in Assamese are bound morphemes. The bound morpheme nprefixes to a root verb and copies its vowel as shown in Table 9.

Table 9 Derivation by the $\mathrm{n}$ - morpheme

\begin{tabular}{|c|c|c|c|c|}
\hline Prefix & Root & Gloss & Prefix+root & Gloss \\
\hline$n-$ & $\mathrm{bv}$ & take & nolJv & do not take \\
\hline$n-$ & pدגר & read & nכрנhv & do not read \\
\hline$n-$ & $k^{h} a v$ & eat & $\mathrm{nak}^{\mathrm{h}} \mathrm{a} \mathrm{v}$ & do not eat \\
\hline$n-$ & $\operatorname{lik}^{h} v$ & write & nilik $^{h} v$ & do not write \\
\hline
\end{tabular}

Table 9 shows derivation of verbs with the help of negative morpheme $\mathbf{n}$-. Barbora (2001:101) explains in detail that negative prefix $\mathbf{n}$ - copies the vowel of the root word. In (7a-b) we have examples of negative sentences in Assamese.
7. (a) $x i \quad$ am $n a-k^{h} a-i$
he mango NEG-eat-3
'He does not eat mango' 


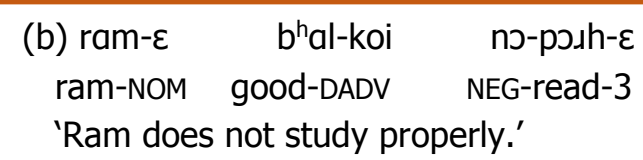

(7a-b) shows derivation of negative verbs in Assamese. In (7a) the derivational morpheme $\mathbf{n}$ - is prefixed to the verb $\mathbf{k}^{\mathbf{h}} \mathbf{a}$ to derive the negative verb nak $\mathbf{k}^{\mathbf{h}} \mathbf{a}$. Here the negative morpheme is $\mathbf{n} . \mathbf{n}$ takes /a/ as a result of vowel copying from the verb root $\mathbf{k}^{\mathbf{h}} \mathbf{a}$. In (7b) the derivational morpheme $\mathbf{n}$ - is prefixed to the verb posh to derive the negative verb nops.sh. Here also we see instance of vowel copying when the negative morpheme $\mathbf{n}$ - copies the vowel /0/ from posh.

\subsubsection{De-adjectival verb}

De-adjectival verb is an instance of derivation of a verb from an adjective. Crystal (2008: 130) defines deadjectival verb as a verb that originates as an adjective but used as verb in sentence structure. In Assamese there are some adjectives which sit in the position of a verb without taking any derivational suffix. However, when they sit in the position of a verb, they take inflectional morphemes like causative, tense, aspect and person markers as shown in (8a-b).

8. (a) pani-khini topst-ซa

water-QTF hot-CAUS2.2P

'Boil the water.'

(b) nitu- $\varepsilon$ saul-bə৯ kumol-a-is- $\varepsilon$

nitu-ERG rice-PL soft-CAUS1-PRG-3

Lit: 'Nitu is softening rice.'

'Nitu is soaking the rice to soften.'

In (8a) the causative - $\boldsymbol{v a}$ is causing indirect causation and in (8b) we have direct causation, where the subject is doing the job of softening the rice. Barbora (2016:115) labels the direct causative -a as CAUS 1 and the indirect causative - $\boldsymbol{-} \mathbf{a}$ as CAUS 2.

\subsection{Derivation of Assamese adjectives}

Derivation of adjectives in Assamese is a very productive process. In Assamese adjectives are derived from noun, adjective and verb.

\subsubsection{De-nominal adjective}

Denominal adjectives are adjectives derived from a base noun. Crystal (2008: 135) defines denominal adjective as adjective that originates as a noun but used as an adjective in a sentence. In Assamese adjectives are formed from nouns by the following class changing derivational suffixes as shown in (9).
9. (a) xi kəa kahini-tø kalpon-ik
(hoi)
he say.NF story-CLF imagination-DADJ

'The story he told is imaginary.'

(b) am bharot-כג دastriys $\mathrm{p}^{\text {hol }}$ (hoi)

mango India-GEN national fruit (be)

'Mango is the national fruit of India.'

(c) situ- $\varepsilon$ suisti-mulJk kam $b^{\text {hal }}$ pa-i.

ritu-ERG creation-DADJ work good get-3 
'Ritu likes creative work.'

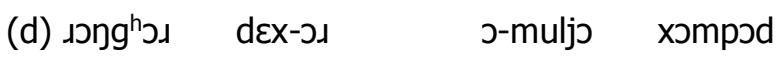
rongghor country-GEN DADJ-price property

'Rongghor is country's priceless property.'

(9a-d) shows how adjectives are derived from nouns in Assamese. In (9a) the noun kolpona 'imagination' is suffixed with the derivational suffix -ik to derive the adjective kalponik 'imaginary'. Derivation of the word kalponik from kolpona shows morphophonemic change where the where the back vowel between close and half close changes to a back open vowel tat is, $/ \mathbf{J} / \rightarrow / \mathbf{a} /$. The word final $\mathbf{a}$ of kolpona is dropped before suffixing -ik. In (9b) the adjective sastıijo 'national' is derived from the noun sastı 'nation'. Here, when the derivational morpheme -ijo is suffixed to the noun دastı vowel dropping takes place as a result of which the word final / $/ \mathrm{J}$ of دastı is dropped before suffixing -ijo. The derivational suffix - mulok that derives the adjective in (9c) is a typical bound morpheme that is actually derived from a noun mul 'root' by suffixing the -ok morpheme. However, mulok is a bound morpheme that derives an adjective from a noun ssisti 'creation' in (9c). (9d) gives an instance of a derivational prefix $\mathbf{\jmath}$ - that derives the adjective $\mathbf{~}$ muljo 'priceless' from a noun muljo 'price'.

\subsubsection{De-nominal adjective with negative connotation}

When bound morphemes ni-, ni.- and -hin are affixed to a noun they derive adjectives and the derived adjectives give the sense of 'devoid of / without something that is referred by the noun'. These are shown with examples in Table 10, 11 and 12.

Table 10 Derivation by ni- morpheme

\begin{tabular}{|c|c|c|c|c|}
\hline Prefix & Root & Gloss & Prefix+root & Gloss \\
\hline ni- & $x J b d \partial_{N}$ & sound & nixJbdכ ${ }_{A D J}$ & silent \\
\hline ni- & xulkJ & fee & nixulkJ $\partial_{A D j}$ & free of cost \\
\hline ni- & $\operatorname{sinta}_{N}$ & worry & nisint ${ }_{\text {ADJ }}$ & worry-less \\
\hline ni- & 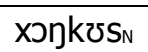 & hesitation & nixכykJكS & without hesitation \\
\hline
\end{tabular}

Table 11 Derivation by niı- morpheme

\begin{tabular}{|c|c|c|c|c|}
\hline Prefix & Root & Gloss & Prefix+root & Gloss \\
\hline nid & $\mathrm{jib}_{\mathrm{N}}$ & life & $n i\lrcorner j i b_{A D J}$ & lifeless \\
\hline ni.d & $\operatorname{gun}_{N}$ & quality & ni.sgun $_{A D J}$ & $\begin{array}{l}\text { something that cannot be } \\
\text { attributed with any quality }\end{array}$ \\
\hline niı & วpJuad $_{\mathrm{N}}$ & crime & ni.љวpدıad ${ }_{A D J}$ & innocent \\
\hline ni.d & $\mathrm{bvd}^{h_{N}}$ & knowledge & niıbəd ${ }^{h}{ }_{A D J}$ & innocent/dull \\
\hline
\end{tabular}

Table 12 Derivation by -hin morpheme

\begin{tabular}{|c|c|c|c|c|}
\hline Root & Gloss & Suffix & Root+suffix & Gloss \\
\hline budd $\mathrm{i}_{\mathrm{N}}$ & intelligence & -hin & buddhihin $_{\text {ADJ }}$ & dull/stupid \\
\hline xoktin & strength & -hin & xJktihinADJ & weak \\
\hline Juth ${ }^{2}{ }^{N}$ & meaning & -hin & Juthohin & meaningless \\
\hline xJbdJN & sound & -hin & $x$ Jbdכhin & soundless/silent \\
\hline
\end{tabular}




\subsubsection{De-verbal adjectives}

As the name suggests, de-verbal adjectives are adjectives realized through derivational process by suffixing a derivational morpheme to a verb. In Table 13, we have instances of derivation of adjectives from verbs.

Table 13 De-verbal adjectives in Assamese

\begin{tabular}{|c|c|c|c|c|}
\hline Root & Gloss & Suffix & Root+Suffix & Gloss \\
\hline גכSV & compose & -ito & גכSitכaDנ & composed \\
\hline kandv & cry & -uxa & kanduıa $A D J$ & cry baby \\
\hline pola v & flee & -כנia & pدادגia ADJ & $\begin{array}{lll}\text { one who flees / } \\
\text { escapist }\end{array}$ \\
\hline
\end{tabular}

Table 13 shows derivation of adjectives from verbs in Assamese with the suffixes -ito, -uıa, ग.jia.

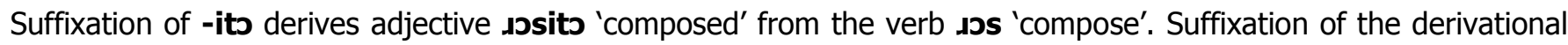
suffix -usa to the verb kand 'cry' derives the adjective kandusa 'cry baby'. Suffixation of -נכia to the verb pola 'flee' derives the adjective polosia 'one who flees'. This derivation in Assamese is shown in examples (10a-d).

10. (a) tumi likh-its pגoman dia
you write-DADJ proof give-2

Lit: 'You give written proof.'

'You provide written proof.'

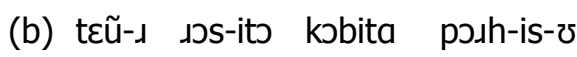

he-GEN compose-DADJ poem read-PRF-1

'I have read poem/poems composed by him.'

(c) loıa-to bor kand-əıa (hoi)

boy-CL very cry- DADJ.M (be)

'The boy is a crybaby.'

(d) szali-zon-i bos kand-əגi (həi)

girl-CL-F very cry- DADJ.F (hoi)

'The girl is a crybaby.'

In (10a) and (10b) the derivational suffix -ito derives an adjective from a verbs lik 'hrite' and ros 'compose'. Derivational suffix -usa derives an adjective kandひsa 'a boy who is a crybaby' from a verb kand 'cry' in (10c). The feminine counterpart of - usa is kand 'cry' in (10d).

\subsubsection{De-adjectival adjective}

De-adjectival adjectives are adjectives derived from adjectives. Affixation of a bound morpheme with adjective changes the meaning of the root adjective and in this process derives another adjective which is shown in Table 14:

Table 14 shows derivation of adjectives from adjectives in Assamese with the prefix -0. The prefix $\mathbf{0}-$

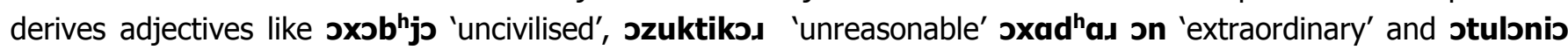

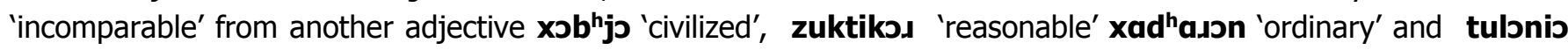
'comparable' respectively. Thus $\mathbf{0}$ - is a class maintaining derivational prefix. Thus we can see that prefix $\mathbf{0}$ - derives an adjective having a negative meaning as well as positive meaning. 
Table 14 Deadjectival adjectives in Assamese

\begin{tabular}{|c|c|c|c|c|}
\hline Root & Gloss & Prefix & Prefix+Root & Gloss \\
\hline$x כ b^{h}{ }^{h}{ }_{A D J}$ & civilized & כ- & ${ } X \mathrm{~b}^{h_{j}}$ & uncivilized \\
\hline ZuktikJ ג ADJ & reasonable & כ- & כzuktikJ ג ADJ & unreasonable \\
\hline xadhadonaDJ & ordinary & כ- & 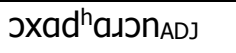 & extraordinary \\
\hline tuloniว & comparable & כ- & o-tulJniว ${ }_{A D J}$ & incomparable \\
\hline
\end{tabular}

However, the morpheme is more productive in deriving adjective having a negative meaning. Sentences (11 a-b) show the derived adjectives occur as a complement in the predicate phrase.

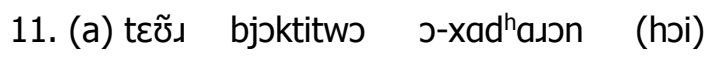

his personality DADJ-common (be)

'His personality is exceptional.'

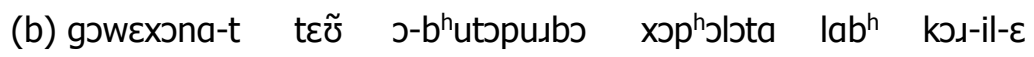

research-LOC he DADJ-former success gain do-PST-3

'He got unprecedented success in research.'

From the above analysis it is evident that $\boldsymbol{\partial -}$ is a very productive derivational morpheme that derives adjective from adjective (see Table 15) and noun form noun (see Table 1). This prefix is more productive in deriving an adjective from another adjective.

\subsection{Derivation of Assamese Adverbs}

Adverbs in Assamese are derived from word categories like noun and adjective by affixing derivational morphemes. In Table 16 we have instances of derived adverbs from nouns:

\subsubsection{Denominal Adverbs}

Denominal adverb is an adverb derived from a noun. Derivation of an adverb from noun is very frequent in Assamese. Morphemes $-r \varepsilon$, and -ai are suffixed with a noun to derive an adverb from a noun which is shown in Table 15.

Table 15 Denominal adverbs in Assamese

\begin{tabular}{|c|c|c|c|c|}
\hline Root & Gloss & Suffix & Root+Suffix & Gloss \\
\hline beg $g_{N}$ & Speed & -ai & begai & speedily \\
\hline nipunsta $_{N}$ & Skill & 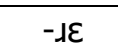 & nipunวtaı $\varepsilon_{\text {ADV }}$ & skilfully \\
\hline
\end{tabular}

Table 15 shows derivation of adverbs from nouns in Assamese with the suffixes -ai, and $-\boldsymbol{\jmath} \varepsilon$. Suffixation of -ai derives the adverb brgai 'quickly, fast, speedily' from the noun bøg 'speed'. Suffixation of $-\boldsymbol{\jmath} \boldsymbol{\varepsilon}$ to the noun nipunota 'skill' derives the adverb nipunotase 'skilfully'. In examples (12 a-b) we have adverbs in the imperative sentence (12a) and (12b).
12. (a) beg-ai zซ-a
speed-DADV go-2P
'Go quickly.'

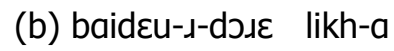 'Write like your sister.' SISTER-GEN-LIKE WRITE-2 
The morpheme -ai can be directly suffixed to the noun to derive an adverb as in (12a). But (12b) shows that the morpheme -dos cannot be suffixed directly to the stem. The genitive morpheme $-\boldsymbol{d}$ is suffixed first with the noun

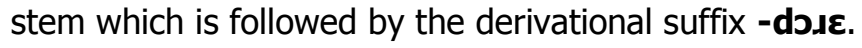

\subsubsection{Deadjectival adverbs}

Following Crystal (2008:130) de-adjectival adverb can be explained as an adverb that originates as an adjectival but can be used as an adverb in a sentence. De-adjectival adverbs is formed with the derivational suffixes -koi and -ai. These two bound forms are very productive in the language

Table 16 Deadjectival adverbs in Assamese

\begin{tabular}{|c|c|c|c|c|}
\hline Root & Gloss & Suffix & Root+Suffix & Gloss \\
\hline siziladj $_{A}$ & neat & $-k o i$ & sizilkoi $_{A D V}$ & neatly \\
\hline$k^{h}{ }^{h} \lambda_{A D J}$ & fast & -koi & k $^{\text {holkoi }}$ & speedily \\
\hline$g^{\text {h}} \partial n_{A D J}$ & dense & -ai & $g^{\text {honai }}{ }_{A D V}$ & densely/frequently \\
\hline bכholadj & broad & -ai & boholaiadv & broadly \\
\hline
\end{tabular}

Table 16 shows derivation of adverbs from adjectives in Assamese with the suffixes -koi, and -ai. Suffixation of -koi to the adjectives sizil 'neat' and $\mathbf{k}^{\text {h}} \mathbf{}$ د. 'fast' derives the adverbs sizilkoi 'neatly' and $\mathbf{k}^{\text {h}}$ ग.skoi'speedily'respectively. Suffixation of -ai to adjectives $\mathbf{g}^{\text {h}} \mathbf{\text { on }}$ 'dense/frequent'and bohol 'broad/wide' derives adverbs $\mathbf{g}^{\text {honai }}$ 'densely/frequently' and boholai 'broadly' respectively. In (13a-c) we have sentences where the adverbs derived by -koi and -ai function as adverb of manner.

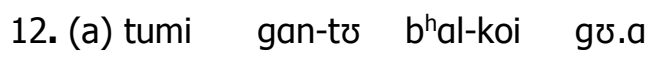

you song-CL good-DADV sing-2

'You sing the song nicely.'

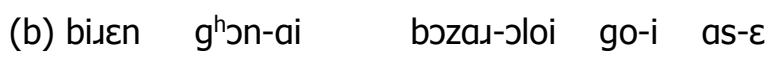

biren dense-DADV market-DAT go-NF exist-3P

'Biren is going to the market frequently.'

(c) tumi $\quad k^{\text {h}}$ गג-koi lik-iboloi sesta kगג-a

you fast-DADV write-INF try do-2

'You try to write fast.'

\subsubsection{Complete reduplication}

In Table 17 we have a few examples of complete repudlication in Assamese. The suffix $-\varepsilon$ adjoins to the adjective and the reduplicated form functions as an adjective

Table 17 Complete reduplication to derive adverbs

\begin{tabular}{|c|c|c|c|c|}
\hline Adjective & Gloss & Suffix & Adverb & Gloss \\
\hline $\mathrm{b}^{\text {hal }}$ & good & $-\varepsilon$ & $\mathrm{b}^{\text {h }} \mathrm{al}-\varepsilon \mathrm{b}^{\mathrm{h}} \mathrm{al}-\varepsilon$ & Safely/nicely/ properly \\
\hline $\mathrm{b} \varepsilon \mathrm{g}$ & quick & $-\varepsilon$ & $\mathrm{b} \varepsilon \mathrm{g}-\varepsilon$ & quickly \\
\hline lahe & slow & & lah $\varepsilon$ lah $\varepsilon$ & slowly \\
\hline
\end{tabular}


In Table 17 we have a reduplicated adverb lahe lahe 'slowly' which does not take the adverbial marker $-\varepsilon$. Complete reduplication is one of the strategies to derive manner adverbs. In (13) the derived adverb indicates the manner in which the subject has arrived.

\begin{tabular}{|c|c|c|c|c|}
\hline 13. (a) & $\begin{array}{l}\text { nogen } \\
\text { nagen }\end{array}$ & $\begin{array}{l}b^{\text {hal- }}-\varepsilon \\
\text { good-DADI }\end{array}$ & $\begin{array}{c}b^{\text {hal }}-\varepsilon \\
\text { good-DADV }\end{array}$ & $\begin{array}{c}\text { pa-l-- }- \text {-hi } \\
\text { get-PST-3-ASS }\end{array}$ \\
\hline
\end{tabular}

\subsubsection{Denominal adverbs}

In Table 18, we have instances of derivation of manner adverbs from nouns. Here too the adverbial marker - koi and the reduplicated marker $-\varepsilon$ suffixes to the noun to derive adverbs.

Table 18 Denominal adverbs in Assamese

\begin{tabular}{|c|c|c|c|c|}
\hline Noun & Gloss & Suffix & Adverb & Gloss \\
\hline xaגiN & row & - koi & xaui-koi & 'in a row' \\
\hline kan $_{N}$ & ear & $-\varepsilon$ & kan $\varepsilon$ kan $\varepsilon$ ADV & 'whisper' \\
\hline
\end{tabular}

The adverbial marker -koi suffixes to the noun xadi 'row' to derive the adverb xasikoi ' in a row'. The suffix $-\boldsymbol{\varepsilon}$ derives the adverb kan $\boldsymbol{\varepsilon}$ kan $\boldsymbol{\varepsilon}$ 'silently whisper in the ear' from the noun kan 'ear'. In (14a-b) the derived adverbs modify the main verbs.

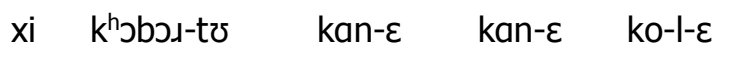

he news-CL ear-DADV ear-DADV tell-PST-3

'Lit: He told the news ear to ear.'

'He whispered the news.'

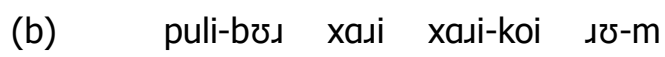

sapling-PL row row-DADV plant-1.FUT

'I will plant the saplings in rows.'

\section{Conclusions}

The analysis of the derivational process in Assamese shows that the language uses both prefixes and suffixes to derive a new category or maintain the same category. Of the two affixation processes suffixation is more productive in the language than prefixation. The class maintaining derivational affixes in the language are:

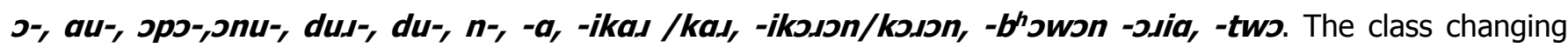
derivational affixes are: -oni, -uoi, -دjia,-uta, -jok/ok, ota, otwo, -two, -ija,-ik, ijo, nis-, ni-, o-, -ito, -usa, -

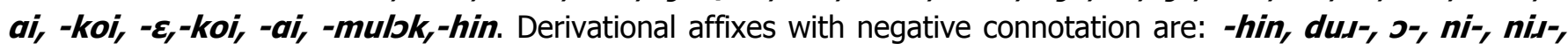
ops-, dur. The prefix $\boldsymbol{\nu}$ - can be both class changing and class maintain. This prefix can also derive words with

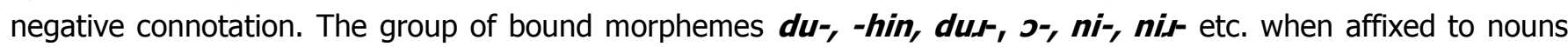
the derived word carries the meaning 'devoid of or absence of the quality referred by the root'. In contrast the negative morpheme $\mathbf{n}$ - is class maintaining and the derived negative verb functions as a matrix verb in a clause. Some derivational morphemes like -oni, -mulık and -õta are very productive in the language. On the other hand morphemes like $-\mathbf{b}^{\mathbf{h}} \mathbf{J}$ won are not very productive.

Morphophonemic change of the stem is observed in cases like naws.ia 'boatman', when the bound

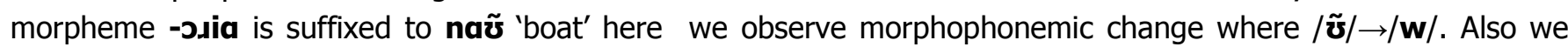
have instances of vowel copying when the negative morpheme $\mathbf{n}$ - is prefixed to a verb root. Also some allomorphs

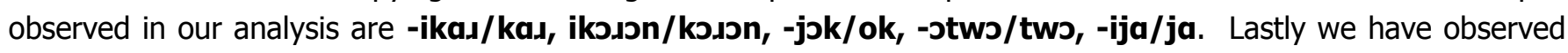
some bound morphemes have the ability to affix with different word categories to derive new words. For example, -two can derive noun from adjective and noun form noun. 


\section{Abbreviation}

$\begin{array}{lll}1 & - & \text { first person } \\ 2 & - & \text { second person } \\ 3 & - & \text { third person } \\ \text { ass } & - & \text { assertive } \\ \text { caus } & - & \text { causative } \\ \text { clf } & - & \text { classifier } \\ \text { col } & - & \text { collective } \\ \text { cp } & - & \text { complimentizer } \\ \text { dadv } & - & \text { deadverbial } \\ \text { dadj } & - & \text { deadjectival } \\ \text { dat } & - & \text { dative } \\ \text { dnom } & - & \text { denominal } \\ \text { dvrb } & - & \text { deverbal } \\ \text { erg } & - & \text { ergative } \\ \text { F } & - & \text { feminine } \\ \text { fut } & - & \text { future } \\ \text { gen } & - & \text { genitive } \\ \text { inf } & - & \text { infinitive } \\ \text { loc } & - & \text { locative } \\ \text { M } & - & \text { masculine } \\ \text { neg } & - & \text { negative } \\ \text { nf } & - & \text { non finite } \\ \text { nmz } & - & \text { nominalizer } \\ \text { prf } & - & \text { perfect } \\ \text { prg } & - & \text { progressive } \\ \text { pst } & - & \text { past } \\ \text { qtf } & - & \text { quantifier } \\ & & -\end{array}$

\section{References}

Anderson, S. R., (1995), A-Morphous Morphology. Cambridge University Press. New York. USA.

Barbora, M. (2001). 'COMPs in Assamese: Implications for Second Language Acquisition'.Ph. D. Thesis, Tezpur University, Tezpur, Assam.

Barbora, M. (2016). 'Causative Constructions in Assamese'. In Barbora, M., and Borah, G., editors, Aspects of Modern Assamese. Pages115-132. Bhabani offset Pvt. Ltd. Guwahati for Tezpur University

Booij, Geert. (2012). The Grammar of Words: An Introduction to Linguistic Morphology. Oxford University Press. UK

Crystal, D. (2008). Dictionary of Linguistics and Phonetics. Blackwell Publishing. UK.

Goswami, G. (1982). The Structure of Assamese. Gaauhati University Press. 
Haspelmath, Martin., and Sims D. Andrea (2010). Understanding Morphology. Hodder Education, London.

Kakati, Banikanta,.(1941). Assamese Its Formation and Development. Guwahati: Govt. of Assam.

Payne, T.E. (2006). Exploring Language Structure: A Student's Guide. CUP.UK.

Trask, R. L. (1999). Key Concepts in Language and Linguistics. Routledge, London. UK.

\section{Funding}

No funding was received for conducting this study.

\section{Conflict of interest}

The authors have no conflicts of interest to declare that they are relevant to the content of this article.

\section{About the License}

(C) The author(s) 2020. The text of this article is open access and licensed under a Creative Commons Attribution 4.0 International License 